\title{
“ESSA DAMA BATE BUÉ” E O CÂNONE LITERÁRIO ANGOLANO
}

\author{
IOLANDA VASILE ${ }^{1}$
}

\begin{abstract}
Essa Dama Bate Bué and the Angolan Literary Canon. A relevant topic for the history of literature, the literary canon has been widely questioned and the Angolan literary canon is no exception, being constantly susceptible to changes. The current paper aims at challenging the Angolan literary canon and defending the necessity of including the novel Essa Dama Bate Bué by Yara Monteiro. Published in 2018, it represents an example of silenced literature about women and guerrilla movements during the war for national independence, the subsequent civil war, and the post-conflict period. The book problematizes the presence of women in national wars, the countless roles they played, but also their integration in the post-colonial society, giving insights into a topic largely ignored in Angolan literature.
\end{abstract}

Keywords: Angola, Angolan women, canon, Yara Monteiro, guerrilla movements

REZUMAT. “Essa Dama Bate Bué” și canonul literar angolez. 0 temă de mare relevanță în istoria literaturii, canonul literar a fost amplu chestionat. La rândul său, canonul literar angolez nu face excepție și este, așa cum e firesc, supus unor schimbări. Articolul de față vine să provoace acest canon angolez și să argumenteze în favoarea includerii operei “Essa Dama Bate Bué”, de Yara Monteiro. Publicat în 2018, romanul reprezintă o literatură redusă la tăcere, despre femei și mișcări de gherilă în timpul războiului pentru independență națională, războiului civil care i-a urmat și în post-conflict. Cartea problematizează prezența femeilor în războaiele naționale, din perspectiva diferitelor roluri pe care le-au avut, precum și integrarea acestora în societatea post-colonială, dând vizibilitate unei tematici ignorate in literatura angoleză.

Cuvinte-cheie: Angola, femei angoleze, canon, Yara Monteiro, mișcări de gherilă

1 Iolanda VASILE é doutoranda e investigadora júnior no Centro de Estudos Sociais. É licenciada em Línguas Estrangeiras (japonês e português) pela Universidade de Bucareste, Roménia. Sua pesquisa de doutoramento se desdobra sobre o papel desempenhado pelas mulheres angolanas durante o eclodir dos movimentos de libertação em Angola entre 1945 e 1961. Email: iolanda.vasile@gmail.com. 


\section{Introdução}

A história recente de Angola, alvo nos últimos anos de muitos estudos nas ciências sociais e humanas, é relatada por norma numa primeira voz masculina. Os debates públicos, os livros memorialísticos e, especialmente a literatura, observam a mesma prática. As escritas de Pepetela, Luandino Vieira, Ruy Duarte de Carvalho ou Manuel Rui, entre outros, representam o cânone duma literatura que afirma o seu lugar de intervenção. Testemunha de tempos históricos conturbados, esta literatura serve para apaziguar o passado, para entendê-lo, ao passo que se busca construir um futuro para todos e todas. Estas memórias coletivas são assim transmitidas para as gerações futuras, que também viveram parte destes traumas e exigem o seu lugar junto da mesa dos e das contadoras de estórias e histórias. Assim, entre as novas vozes que contam com e sobre Angola destaca-se a de Yara Monteiro. Ida muito jovem para Portugal, junto com a sua família, a autora deparou-se com memórias afetivas contadas, que determinaram a sua trajetória pessoal e autoral. 0 propósito deste ensaio é de analisar o primeiro romance da escritora e mostrar como este rompe com uma ideia de cânone literário angolano, colocando pela primeira vez no seu cerne figuras femininas com agência, isto é mulheres que são as personagens principais das suas próprias histórias de vida.

\section{Cânone, literatura angolana e "Essa Dama Bate Bué"}

A ideia de cânone literário foi e continua sendo um tema de grande interesse para os estudiosos e críticos literários no mundo inteiro. Já gerou vários debates frutuosos e criou catalogações que dividiram a literatura e os romances em função de normas aleatórias, vinculadas às realidades socioculturais meramente eurocêntricas.

Independentemente do seu cunho, por vezes com algumas adaptações que levam em conta as realidades locais, esta identificação literária foi aplicada à maior parte dos sistemas literários no mundo, e o caso angolano não faz exceção. Há textos de há mais de 20 anos, onde investigadores angolanos e internacionais discutem a história da literatura angolana, desde os seus primórdios - passando pelas escritas coloniais ou de cunho colonial-, até à literatura angolana contemporânea. Se ao começo estes debates teciam-se em torno daquilo que podia ou não constituir o corpus duma literatura angolana verdadeiramente nacional, por consequência também dum cânone nacional, com a amplitude que os estudos pós-coloniais ganharam, o debate centra-se hoje em dia na identificação dum cânone literário pós-colonial crítico e inclusivo. Nota-se, naturalmente, uma progressão, desde a necessidade de criação duma história inclusiva e exaustiva da literatura - iniciada, em Angola, por Boaventura Cardoso -, até ao interesse por uma abordagem pós-colonial crítica desta 
indexação. Graças à esta perspetiva crítica pós-colonial, a própria noção de cânone literário ganha em profundidade e deixa de ter como referências teóricas os textos eurocêntricos, concentrando-se na identificação de temas nacionais escritos de novas perspetivas de género, geracionais, temáticos e a partir de geografias nacionais ou internacionais, sempre referindo direta ou indiretamente os espaços nacionais. Como a professora Ana Mafalda Leite lembra num texto já em 2012:

Este novo quadro que se desenha no âmbito dos estudos literários africanos vai, de certo, permitir questionar algumas das posições mais ou menos essencialistas e "supostamente" canônicas da recepção (...). Critérios como local de nascimento, temas, repertórios de formas nativizantes, língua, posturas nacionalistas ou proto-nacionalistas, não poderão ser de agora em diante critérios únicos, adequados à integração ou não de obra, autor, época ou geração, em um sistema literário (Leite, 2012).

Aponta-se, portanto, para a criação de um cânone mais abrangente, menos ideológico, contudo situado, politizado e de cunho crítico, independentemente da geografia física do autor. Desta forma, o cânone passa a sair da linearidade histórica determinada tão profundamente em Angola pela luta de libertação nacional e a tentar ser definido por outras dinâmicas de destaque na contemporaneidade, como as lutas pós-coloniais de género e classe socioeconómica.

Há em Angola, como em qualquer outro país, uma plêiade de escritores e escritoras reconhecidos/as como parte do cânone literário daquele país, como também há um grande corpus de literatura oral cuja identificação não é nominal, nem exaustiva. Nomes como António Jacinto, Alda Lara, Pepetela, Luandino Vieira, Ana Paula Tavares, Ruy Duarte de Carvalho e Manuel Rui fazem incontestavelmente parte do cânone literário angolano.

0 propósito deste ensaio não é questionar este cânone literário, por mais arbitrário que seja, mas antes observar a pouca presença das mulheres, tanto no que diz respeito aos nomes, como também aos tópicos abordados, que raramente têm como temas centrais as personagens femininas. E, ao observar, questionar esta ausência e discutir o romance "Essa Dama Bate Bué", que tem o potencial de romper com a ideia de cânone literário angolano.

Nascida em Angola, e radicada desde muito nova em Portugal, Yara Monteiro, escritora de nacionalidade portuguesa e ascendência angolana, tem surgido no mercado literário num momento em que a reescrita da história angolana está a ganhar mais títulos inclusivos de vozes e autorias femininas. ${ }^{2} \mathrm{O}$ seu primeiro romance "Essa Dama Bate Bué" conta a história da Vitória Queiroz da Fonseca, jovem mulher negra angolana lésbica que, junto com a sua família, vem

2 Para uma abordagem mais abrangente, ver, entre outros: Dya Kassembe \& Paulina Chiziane (2008) e Margarida Paredes (2014). 
morar desde pequena para Portugal, por conta do conflito em Angola. A presença do conflito, por causa da guerra pela libertação nacional e em seguida da guerra civil, é o pano de fundo do romance publicado pela Guerra e Paz em 2018.

Criada em Portugal pelos avós, a simbolicamente chamada Vitória, regressa para Angola para encontrar a mãe que nunca conheceu. "Rosa Chitula, minha mãe, mais do que a mim, amou Angola e por ela combateu." (Monteiro 2018, 9) A antiga guerrilheira deixa a filha ao cuidado dos avós e volta a lutar pelo seu país. Vitória retorna para Angola naquilo que é a procura da mãe, mas também numa busca pessoal pelas raízes, cultura, caminho para curar os traumas pessoais e a quase-catarse das várias gerações que cruzam o caminho de Vitória.

Nascida no seio de uma família tradicional, cujo pai estava a favor do governo colonial, considerando-se "assimilado e, acima de tudo, português" ( $p$. 12), Rosa Chitula rompe com o papel tradicional atribuído às mulheres: “(...) era talha grossa e, para seu desagrado [do pai], não gostava da vida caseira e dos afazeres domésticos" (Monteiro 2018, 10). Por isso, o pai encarrega-lhe com alguns trabalhos administrativos junto dos "nativos" 3 na altura do eclodir do nacionalismo angolano. Através da rádio, jornais e alguns panfletos a filha inteirase dos “(...) saques desordenados, as violações, os raptos e o aumento da tensão entre brancos e negros." (Monteiro 2018, 12). Mais, Rosa começa a participar em manifestações: "(...) sua filha, encontrava-se na primeira fila do protesto e empunhava um cartaz com a frase: "Angola para os angolanos. (Monteiro 2018, 12)". Foi o começo das suas batalhas e da fuga da casa paternal. Havia de regressar 15 anos mais tarde, para entregar a filha de dois anos aos pais, e nunca mais aparecer. Em 1980, no meio de um país em plena guerra civil, os avós decidem deixar tudo para trás:

Quando se foge da guerra, só se leva o peso que se consegue carregar. No caso, dona Bia, Hermínia e Cândida eram excesso de carga para os Queiroz da Fonseca. A partida da nossa família arrasta consigo o ónus da morte de quem nos deu a vida, mas agora decidimos deixar para trás. (Monteiro 2018, 17)

Os pertences, como as pessoas que sempre cuidaram da vida deles em Luanda, são deixados para trás e uma nova vida em Portugal começa, sempre com o sentimento da perda. A personalidade forte da mãe, que tinha escolhido a revolução e a esta se tinha dedicado, contrasta com a atitude de desistência dos avós da Vitória, que não entendem a luta pela libertação, nem o abandono dos portugueses pois, no pensar do avô o "nacionalismo [era] uma reviravolta insidiosa contra a serenidade colonial. No entanto, ficava pasmado com a atitude de Portugal: lavara as mãos." (Monteiro 2018, 11)

3 Referência ao Estatuto do Indigenato (1926-1961). 
Anos mais tarde, Vitória, filha da sua mãe, faz as suas próprias escolhas e regressa à Luanda de "poeira e cimento" (Monteiro 2018, 28); a cidade que abarca todos os sonhos da revolução e populações de todo o território nacional. $\mathrm{Na}$ terra aparentemente inóspita, Vitória constrói o puzzle das suas identidades naquilo que é a procura da sua mãe. Vitória procura a mãe e no processo descobre Luanda, as suas gentes vindas de todo o país, a vida dura das mulheres angolanas, as histórias sobre os seus passados e as suas lutas no presente. Luanda partilha da história do país, pois a capital mistura-se com as pessoas e as pessoas com a cidade, que uma vez mais personifica o corpo feminino do país "Luanda minha dama. Bates bué!" (Monteiro 2018, 51) E é no meio deste turbilhão que Vitória é obrigada a retrabalhar as suas várias identidades, a de mulher negra, num país que a vê "clara", e a de mulher lésbica, identidade esta que sempre permanece oculta.

Como a própria autora afirma, este não é um livro autobiográfico, mas

My family intergenerational memories: on colonialism, liberation war, survival, resistance; as well as my personal memories, and experience in identity, racism and cultural diversity - in Portugal and Angola - were the foundation for my book narrative. (Monteiro 2019, 51)

Yara Monteiro, traz assim uma experiência angolana de "fora", para falar de temas muito presentes na sociedade angolana atual: o lugar das mulheres antes e depois dos conflitos, na construção da sociedade atual e na vida das suas famílias. Salienta-se que estes elementos são vistos com o olhar de fora, às vezes de estranheza, mas com curiosidade e indagação. A "autóctone" aprende a reacomodar-se com algo conhecido, questionando o "não-falado", pois os olhos de fora sempre beneficiaram desse privilégio.

Um dos principais critérios de análise quando se trata do cânone literário é a prova do tempo. Apesar de ser uma obra recente, este critério padece face à relevância do tema e dos grupos representados na obra. Partindo do pressuposto que a literatura se apresenta como uma janela sociocultural de uma determinada sociedade ou de um lugar, e que o cânone procura fixar no tempo esta representação, é imperioso olhar para "Essa Dama Bate Bué" com sendo uma obra que veio preencher um lugar vazio de fala e representação dos vários papéis que as mulheres angolanas tiveram naquilo que foi o longo processo de independência e (re)construção do novo país.

Dentro destas funções, destaca-se o de mulheres guerrilheiras, com todas as valências e consequências ao nível do microuniverso familiar e social. E a pergunta que surge, quase automaticamente, é porquê esta obra foi escrita de fora para dentro? Porquê desta história ter sido primeiro criada na diáspora e não aparece na literatura escrita em Angola? Porquê é preciso este olhar de 
fora para trazer aquilo que o "Herói” do realizador angolano Zezé Gamboa tenta transpor também: uma vida em pós-guerra, sem ideais, sem aspirações, sem reconhecimento, sem família e sem amparo? O filme do Gamboa tem como personagem um antigo combatente esquecido pelo país pelo qual lutou, que, também com uma invalidade física, já "não pode" ocupar nenhum espaço ou função na sociedade, uma vez a guerra acabada. Portanto, o ex-guerilheiro experimenta um outro tipo de violência em pós-guerra, uma que tem as suas consequências tanto no conflito inicial, enquanto reflexo do colonialismo, como também no leque de conflitos nascidos da luta pela sobrevivência diária na independência. 0 romance da Yara Monteiro ganha o mesmo poder de representação quando traz esta cisão entre as famílias e a sociedade para a literatura, mas colocando no centro várias personagens femininas. São elas, as guerrilheiras angolanas, as "heroínas sem nome", ${ }^{4}$ como o texto lembra:

- A mãe era combatente. A minha família não sabe nada dela desde o final dos anos setenta.

- Muitas camaradas lutaram por este país. Heroínas. (Monteiro 2018, 99)

A invalidez das antigas guerrilheiras representadas no romance não é física, contudo os seus lugares na sociedade foram dificilmente conquistados em pós-guerra e a ligação com as famílias e a reintegração na sociedade fica algo ainda por atingir. Se no "Herói" as famílias tentam encontrar-se através dos programas TV ou rádio, a mesma simbologia transparece no livro supracitado:

A senhorita Vitória Queiroz da Fonseca procura a sua mãe, Rosa Chitula Queiroz da Fonseca, e a sua tia Juliana Tijamba. (...) Vamos unir esta família minha gente! A paz traz a união das famílias. Continue connosco na frequência 93.5 FM... (Monteiro 2018, 127)

Os paralelos com o filme fazem entender que a literatura necessitou de 14 anos a mais para retrabalhar este tema e mudar-lhe o foco nas personagens femininas. De igual modo, associar um dos filmes angolanos mais icónicos com um livro cuja autora é portuguesa de ascendência angolana, coloca em questão a pouca relevância da nacionalidade para a escrita destas histórias e a necessidade de expansão do cânone, uma vez que a literatura escrita por autoras/es nacionais

4 Faz-se referência às cinco mártires guerrilheiras assassinadas em campo de batalha em 1966, em plena luta pela libertação nacional: Deolinda Rodrigues, Irene Cohen, Engrácia dos Santos, Teresa Afonso e Lucrécia Paim. As cinco heroínas, integrantes do Esquadrão Kamy, são referência da participação das mulheres na luta pela libertação nacional. Para além de exposições fotográficas, peças de teatro, estátuas e menções musicais, há também livros que lembram a presença destas valentes mulheres na luta pela libertação nacional. Ver: Deolinda Rodrigues (2003; 2004) e Rodriguez (2014). 
não dá conta de todo o repertório de situações e personagens da realidade angolana pós-colonial.

E voltando à literatura e ao cânone, um dos romances mais emblemáticos da literatura nacional angolana, e de certeza, um que faz parte do cânone, é a "A Geração da Utopia", de Pepetela. Ao descrever os anos do eclodir da luta pela libertação nacional, como também o longo período conturbado que se seguiu, Pepetela cria a personagem Sara, angolana, branca, estudante no exílio, uma das jovens do seu grupo de amigos que imaginaram a independência a partir de fora. Personagem importante, coadjuvante, mas cuja história pessoal não é central no romance, Sara é acompanhada por outras figuras femininas: a sua amiga Marta, a mais comprometida com a luta, Fernanda, que fica à margem das questões políticas, Luzia, personagem apagada que vive na sombra do marido, e Mussole, enquanto figura feminina idealizada. Não por último, surge Judite, a filha de Sara, enquanto símbolo da renovação. Um livro politicamente engajado, representando várias gerações de sonhos falhados, permanece entre os primeiros e poucos na literatura angolana a tentar dar um outro tipo de voz às suas personagens femininas. E, neste ponto, uma analogia pode ser feita tanto entre a Rosa e a Sara, como entre Judite e Vitória, entre as várias facetas da luta, de fora para dentro e dentro do território nacional. Rosa e Sara são faces da mesma moeda. Sara estava a espera que a Rosa tivesse o seu nome e lugar na literatura angolana e no seu cânone, pois ela existiu na realidade da luta pela libertação em Angola. Não só existiu, como teve vários nomes, tantos que se perderam nos campos de batalha, ao lado dos seus companheiros, como foi o caso das mulheres do famoso esquadrão feminino Kamy, que caíram em luta em 1966. Como bem afirmaram as mulheres entrevistadas no "Livro da Paz da Mulher Angolana":

Mas agora que a guerra terminou os homens remetem-nos de novo, ao silêncio das nossas cozinhas. Se no processo da guerra nós mostramos a nossa valentia, porque é que hoje dificultam a nossa integração tanto na vida pública, como na política. (Kassembe \& Chiziane 2008: 20)

Apesar da criação da organização da mulher angolana (OMA) em 1962, o envolvimento mais amplo das mulheres na vida pública e política ainda demora a acontecer.

É este espaço do silêncio que até hoje também faltava na literatura. Rosa encontrou Sara e juntas contam uma história mais inclusiva da história angolana, a partir da literatura. Enquanto a história da Sara nos deixa sonhar talvez com um futuro melhor, a história da Rosa dá o próximo passo e fala da violência da guerra, no contexto pós-colonial. Rosa abandona a filha, a deixa com os avos, cometendo assim o primeiro ato de violência da vida da sua filha. A obra problematiza assim, um ato de abandono, da própria mãe, numa altura em que, em situações de conflito, as mães eram de todas e todos e abarcavam 
metaforicamente as necessidades alheias. Monteiro traz à tona um tema tabu: a violência cometida pelas mulheres contra outras mulheres (Sousa 2020), como perpetuação da violência colonial e geracional. A guerra e a violência, de uma forma ou outra, permanecem na vida das mulheres ex-guerrilheiras, como relata umas das companheiras de luta da Rosa:

Mamã Ju considera que, na Guerra, a morte pode até ser o melhor destino. Ela ou o esquecimento. Está viva e nunca se esqueceu. Para ela, a Guerra ainda não tinha ficado para trás. Conta que nos primeiros combates não se acredita na truculência da Guerra. Vive-se da utopia, do sonho. Isso acontece até que se tenha de matar para não se ser morto. Na Guerra, matar não chega. É massacrar, torturar, mutilar e violar. (Monteiro 2018, 154)

Este depoimento lembra o grande livro de testemunhos orais das mulheres russas que lutaram na Segunda Grande Guerra, da Svetlana Alexievich. O impressionante acervo de entrevistas lembra que a guerra é a mesma em qualquer parte do mundo e em qualquer altura. Os seus traumas físicos e psicológicos se estendem para além das fronteiras físicas das guerras e não desaparecem com o fim do conflito. Os conflitos são perpetuados na sociedade e reverberados pelas antigas e antigos combatentes. A guerra coletiva é sempre também pessoal.

Vitória também complementa Judite, as duas sendo simultaneamente filhas do sonho utópico e da atualidade. Ao passo que Judite possa personificar a esperança num futuro sonhado pela geração dos seus pais, a Vitória é o presente situado, que se busca entender a si próprio através do questionar do passado. Pela primeira vez, a urgência de construir um futuro diferente, melhor, encontra o espaço para colocar perguntas e observar com mais cuidado e sinceridade os erros passados e presentes. Como no caso das suas mães (da nação), Judite e Vitória são filhas do mesmo país diverso e em perpétuo processo de transformação e espera "Espera, Vitória. Espera só. És de um povo que ainda está à espera, que espera, sempre." (Monteiro 2018, 206)

Mas Vitória não se conforma com a espera e começa a procurar a mãe e a conhecê-la através das histórias das suas camaradas de luta: "- Conheci a tua mãe quando mudei de pelotão. Camarada Rosa Chitula. "Dinamite a própria." Era assim que se apresentava, com voz grossa de comando." (Monteiro 2018, 158) Apesar de, por vezes, condenar a violência de ter sido abandonada, Vitória adivinha as difíceis circunstâncias da vida da sua mãe e o contexto em que ela nasceu, fruto de uma violação.

- Nem todos respeitavam a tua mãe. Como era mulher sabes como é? 0 Palanca era um deles. Gostava de a humilhar.

- Mas as mulheres também combatiam - admira-se Vitória com comentário.

- Mesmo assim. Achavam que éramos inferiores. (...) 
- O Palanca humilhava-nos. Um dia, a tua mãe fatigou-se e disparou para matar.

- 0 que ele fez?

- Queria dormir com ela. (Monteiro 2018, 160)

O relato lembra a justaposição das múltiplas formas de violência sofridas pelas mulheres, tanto por parte do colonialismo, como por parte da estrutura da própria sociedade angolana grosso modo que, na sua vertente tradicional, atribui às mulheres os mesmos lugares subsumidos na família e na sociedade. Em contexto de guerra, estas violências contra as mulheres muitas vezes se traduzem também em atos de violência sexual e de género. No entanto, e paradoxalmente, ao retratar estas violências o livro reverte o lugar de vítima da mulher, falando do poder de agir e tomar decisões nas suas vidas, dentro das limitações impostas ou determinadas pela própria situação de violência. $\mathrm{Na}$ aceção comum, tradicional, as guerras são dos homens, portanto as violências também. Até na violência parece que as mulheres não conseguem encontrar o seu lugar. Mas a realidade existe para além dos binarismos e dos lugares predeterminados e, entre outros,

“(...) the abuse and its effects were caused by women on other women as the outcome of external forms of violence associated with colonial and postcolonial conditions." (Sousa, 2020:202)

Neste contexto, Vitória encarna, na sua complexa luta interna de autodescoberta, não tanto os sonhos duma inteira geração, como no caso da Judite, filha de Sara, mas os vários traumas geracionais herdados das mulheres que experimentaram no corpo e na alma os traumas do colonialismo e da pósindependência. Enquanto os traumas representam o peso de gerações, a luta interna é extremamente pessoal e a resolução do conflito se torna possível quando a dor é partilhada publicamente. As histórias que as companheiras da sua mãe contam servem também de testemunho. Elas encontram na Vitória a interlocutora interessada que faltava. Finalmente, o peso do passado é liberado através do testemunho oral. Uma ligação com a mãe, com o passado, mas também com as raízes angolanas se estabelece.

Como num verdadeiro trabalho de investigação académica, o testemunho oral é completado no livro pela visita que a Vitória faz aos arquivos, onde encontra relatos visuais de antigas guerrilheiras.

A rectidão da postura mostra o orgulho da responsabilidade. Têm sempre os lábios cerrados. Tão cerrados que parecem cosidos com corda de sisal. As camaradas não se asfixiam, mas também não falam os seus queixumes de mulher. Dentro de alguns dos processos, estão certidões de nascimento de crianças. Imagino-as a carregar a arma e a criança, como o fez a mãe. 
Escrita em algumas capas do arquivo, está a palavra "falecida". 0 punho que a desenhou é como se fosse a ferida por onde o sangue se esvazia. 0 tempo tudo transforma em cicatriz. (Monteiro 2018, 115)

Considerando a história da literatura angolana, salienta-se que as personagens femininas nunca faltaram nesta literatura, tanto colonial, de oposição, como pós-colonial. Talvez, entre os primeiros títulos que retratam mulheres, sem ser da perspetiva duma literatura de cunho colonial, é "Luuanda" de Luandino Vieira. As personagens femininas do Vieira são geralmente urbanas, coloridas, presentes, fortes, ocupam todo o espaço dos contos em que vivem, pois têm de tratar de tudo: da casa, da comunidade, dos filhos seus e alheios, do bairro, da comida, do equilíbrio da narrativa trazendo a normalidade no meio de situações árduas de vida. Boaventura Cardoso, por sua vez, completa o quadro feminino urbano com figuras femininas fortes, que também lutam pelo seu dia a dia no mundo colonial. As mulheres são assim representadas como pertencentes a certos espaços - a casa, ao quintal - e associadas com certas profissões - mãe, quitandeira, esposa, filha, cunhada, irmã, entre outras. E passamos assim pelo leque das representações da mulher na literatura angolana, desde a ocupante e governante do espaço da casa, do quintal e da lavra até ao espaço de luta na batalha propriamente dita.

Portanto, as mulheres angolanas se apresentam, na sua diversidade, como um grupo não-homogéneo, com múltiplas funções tanto na luta ativa, como também nas trincheiras da vida, oferecendo, por um lado, uma "normalidade" em tempos de guerra, e por outro, numa leitura mais atenta, uma representação da violência histórica e geracional herdada, mas também permitem a capacidade de retrabalhar este trauma comum. As mulheres possibilitam desta forma tanto a luta, como a sobrevivência.

\section{Em jeito de conclusão: para uma mudança de paradigma}

Se há vinte anos atrás os professores Pires Laranjeira e Luís Kandjimbo dialogavam através de artigos que questionavam justamente a formação de um cânone literário angolano e os elementos que o possam definir, hoje em dia as questões que se colocam são: como podemos descolonizar este cânone e atualizá-lo para que seja inclusivo? Mais, como fazer justiça àquilo que foi e é a realidade da literatura angolana para além das suas fronteiras nacionais? Como lembrava a professora Ana Maria Martinho, "Essa Dama Bate Bué" permite "fundamentar novas modalidades de leitura crítica"? (p. 32)

Cabe aqui fazer uso do conceito de "pluralismo cultural" que o professor Kandjimbo empregava para referir-se à necessidade de inclusão no cânone literário angolano de obras multiétnicas e plurilíngues, provenientes dos três segmentos 
da literatura angolana: textos orais, textos literários escritos em línguas nacionais e textos literários escritos em português (Kandjimbo 2001ạ , 6). "Essa Dama Bate Bué" contempla um outro espaço, não incluído nesta categorização, mas que faz uso do pluralismo cultural representado pela diáspora angolana.

Há neste momento fora de Angola escritoras e escritores ${ }^{5}$ que escrevem a partir das memórias que lhe foram contadas pela geração dos seus pais e dos seus avós. Livros como "Essa Dama Bate Bué", (2018) de Yara Monteiro, "Luanda, Lisboa, Paraíso" (2018) de Djaimilia Pereira de Almeida e "Debaixo da nossa pele" (2017) de Joaquim Arena fazem a curta lista de Obras Referencias da Literatura Portuguesa, elaborada pela comissão que organiza a Linha de Apoio à Tradução e Edição do Camões - Instituto da Cooperação e da Língua, I. P. e a Direção-Geral do Livro, dos Arquivos e das Bibliotecas (DGLAB). Entre a lista de 17 subdomínios, os três autores supracitados são enquadrados na categoria "Paisagens afropolitanas", uma referência clara ao inglês "afropolitans", termo cunhado inicialmente por Taiye Selasi e retrabalhado na academia, entre outros, por Achille Mbembe (2007). Por si só valeria um ensaio separado, ainda mais quando usado neste contexto. No entanto, vale notar o reconhecimento que o livro de Monteiro recebeu quase desde a sua publicação. 0 livro está agora pela segunda vez a integrar esta lista e em 2020 foi apoiada a sua tradução através deste programa em Itália e na África de Sul. A sua presença em festivais internacionais como o Fliaraxá, no Brasil, ou o Afrolit Sans Frontières, um novo festival literário online, e em inúmeros outros encontros e entrevistas, mostram a curiosidade que o livro suscitou, a necessidade de ele existir num contexto de mais expansão e abertura para com memórias e pós-memórias transterritoriais. É importante como se autoidentifica esta nova geração que vive na diáspora, mas o seu verdadeiro contributo está na interpelação que consegue fazer dos seus países de origem e de adoção.

As escritoras e escritores angolanos na diáspora, sejam eles de literatura, rap ou outras formas de expressão artística, buscam resgatar este passado, colocando-o contra as suas próprias lembranças e perceções, a partir do seu locus de enunciação, enquanto cidadãos poli-identitários, transitando vários mundos e espaços culturais com impacto na sua trajetória pessoal. Yara Monteiro faz parte desta categoria e afirma não se poder dissociar nem da história nacional de Angola, nem de Portugal (Monteiro, 2020). Enquanto escritora presente nos espaços literários pelo mundo afora, mostra muito bem uma Angola que muito esperou por ser contada e ter mais visibilidade: uma Angola no feminino, que já merece o seu lugar no cânone literário do país.

5 Kalaf Epalanga, Djaimilia Pereira de Almeida, entre outros. 


\section{REFERÊNCIAS BIBLIOGRÁFICAS}

Alexievich, Svetlana. 2017. The Unowmanly Face of War. An Oral History of Women in World War II. Necw York: Random House.

Kandjimbo, Luís. 2001a. "A Literatura Angola, a Formação de um Cânone Literário Mínimo de Língua Portuguesa e as Estratégias da Sua Difusão e Ensino". Publicado no site da União dos Escritores Angolanos. Consultado a 5 de março de 2020: https://www.ueangola.com/criticas-e-ensaios/item/58-a-literatura-angola-aformação-de-um-cânone-literário-m\%C3\%ADnimo-de-1\%C3\%ADnguaportuguesa-e-as-estratégias-da-sua-difusão-e-ensino*

Kandjimbo, Luís. 2001b. "Para uma breve história da ficção narrativa angolana nos últimos cinquenta anos". In Revista de Filología Románica. № Extra 2.161-84.

Kandjimbo, Luís. 2015. "A Disciplinarização da Literatura Angolana: História, Cânones, Discursos Legitimadores e Estatuto Disciplinar". In Estudos Literários 5: 49-103.

Kassembe, Dya; Chiziane, Paulina (org.). 2008. O Livro da Paz da Mulher Angolana. Luanda: Nzila. Laranjeira, Pires (sem ano). "Literatura, Cânone e Poder Político". Publicado no site da União dos Escritores Angolanos. Consultadoc a 5 de março de 2020: https://www.ueangola.com/criticas-e-ensaios/item/82-literatura-cânone-e-poder-politico

Leite, Ana Mafalda. 2012. "Cânone e considerações em torno de Histórias da Literatura”. In Revista Diadorim. 11: 161-168.

Martinho, Ana Maria. 2015. “Textos de António Jacinto - Revisitação de um Cânone Necessário à Compreensão da História Literária Angolana". In António Jacinto e a sua época. A modernidade nas literaturas africanas em língua portuguesa, editado por Ana Paula Tavares, Fabio Mario da Silva e Luís da Cunha Pinheiro, Lisboa: Centro de Literaturas e Culturas Lusófonas e Europeias, Faculdade de Letras da Universidade de Lisboa. 29-40.

Mbembe, Mbembe, A. 2007. "Afropolitanism”. In Africa Remix, editado por Simon Njami e Lucy Durin. Johannesburg: jacana Media.

Monteiro, Yara. 2018. Essa Dama Bate Bué. Lisboa: Guerra \& Paz.

Monteiro, Yara, 2019. HERitage - Family memories in the novel "Essa Dama Bate Bué!". In Carvalho, Apolo et al. Book of Abstracts of the 7th Afroeuropeans network conference. Lisbon: CIES, ISCTE-IUL.

Paredes, Margarida. 2014. Mulheres na luta armada em Angola: Memória, cultura e emancipação. Tese de doutoramento. Lisboa: Instituto Universitário de Lisboa (ISCTE-IUL).

Pepetela. 1992. A geração da utopia. Lisboa: Dom Quixote.

Rodrigues, Deolinda. 2003. Diário de um exílio sem regresso. Luanda: Nzila.

Rodrigues, Deolinda. 2004. As Cartas de Langidila e outros documentos. Luanda: Nzila.

Rodriguez, Limbânia Jiménez. 2014. Heroínas de Angola. Luanda: Mayamba.

Sousa, Sandra. 2020. "Silenced violence in the feminine: a reading of Yara Monteiro's Essa Dama Bate Bué!”. In Revista Diadorim, 22: 198-211.

Vieira, Luandino. 2004. Luuanda: estórias. Lisboa: Caminho.

\section{FILME}

O Herói, Zezé Gamboa, 2004.

\section{ENTREVISTA}

Conversa com José Eduardo Agualusa e Yara Monteiro, no âmbito da 5. Edição da Festa do Livro, iniciativa da @AmadoraCidade. 10 de setembro de 2020. https://www.facebook.com/ UA.DLC/videos/1032021167233883 Consultado em 27 de março de 2021. 